\title{
Meta-analysis of transcriptomic responses as a means to identify pulmonary disease outcomes for engineered nanomaterials
}

\author{
Jake Nikota', Andrew Williams ${ }^{1}$, Carole L. Yauk' ${ }^{1}$ Håkan Wallin²,3, Ulla Vogel ${ }^{2,4}$ and Sabina Halappanavar ${ }^{1 *}$
}

\begin{abstract}
Background: The increasing use of engineered nanomaterials (ENMs) of varying physical and chemical characteristics poses a great challenge for screening and assessing the potential pathology induced by these materials, necessitating novel toxicological approaches. Toxicogenomics measures changes in mRNA levels in cells and tissues following exposure to toxic substances. The resulting information on altered gene expression profiles, associated pathways, and the doses at which these changes occur, are used to identify the underlying mechanisms of toxicity and to predict disease outcomes. We evaluated the applicability of toxicogenomics data in identifying potential lungspecific (genomic datasets are currently available from experiments where mice have been exposed to various ENMs through this common route of exposure) disease outcomes following exposure to ENMs.

Methods: Seven toxicogenomics studies describing mouse pulmonary responses over time following intra-tracheal exposure to increasing doses of carbon nanotubes (CNTs), carbon black, and titanium dioxide $\left(\mathrm{TiO}_{2}\right.$ ) nanoparticles of varying properties were examined to understand underlying mechanisms of toxicity. mRNA profiles from these studies were compared to the publicly available datasets of 15 other mouse models of lung injury/diseases induced by various agents including bleomycin, ovalbumin, TNFa, lipopolysaccharide, bacterial infection, and welding fumes to delineate the implications of ENM-perturbed biological processes to disease pathogenesis in lungs.

Results: The meta-analysis revealed two distinct clusters - one driven by $\mathrm{TiO}_{2}$ and the other by CNTs. Unsupervised clustering of the genes showing significant expression changes revealed that CNT response clustered with bleomycin injury and bacterial infection models, both of which are known to induce lung fibrosis, in a post-exposure-time dependent manner, irrespective of the CNT's physical-chemical properties. $\mathrm{TiO}_{2}$ samples clustered separately from CNTs and disease models.
\end{abstract}

Conclusions: These results indicate that in the absence of apical toxicity data, a tiered strategy beginning with short term, in vivo tissue transcriptomics profiling can effectively and efficiently screen new ENMs that have a higher probability of inducing pulmonary pathogenesis.

Keywords: Nanomaterials, Toxicogenomics, Carbon nanotubes, Carbon black, $\mathrm{TiO}_{2}$ nanoparticles, Lung disease, Lung fibrosis

\footnotetext{
* Correspondence: sabina.halappanavar@hc-sc.gc.ca

${ }^{1}$ Environmental Health Science and Research Bureau, Health Canada, Ottawa,

ON K1A 0K9, Canada

Full list of author information is available at the end of the article
} 


\section{Background}

Commercial applications of engineered nanomaterials (ENMs) continue to grow in the biomedical and manufacturing fields, resulting in an increased demand for synthesis of raw ENMs, increased potential for their release into the environment, and enhanced risk of human exposure [1].

Within the context of their nano size (1-100 nm), ENMs can be synthesized in different shapes, and with different surface charges and functionalization, all of which are shown to influence ENM-induced toxicity [2]. While there is now evidence showing that pulmonary exposure to ENMs is more hazardous than pulmonary exposure to larger particles of the same chemical composition [3-5], the implications of the observed response to adverse outcomes of regulatory importance are not understood. In addition to the inability to extrapolate toxicity data from bulk materials to ENMs, it is also unclear as to which extent toxicity data measured for a select set of ENMs can be generalized to other forms of ENMs (i.e., how to group and rank ENMs with different physicochemical characteristics). Furthermore, critical toxicological data concerning ENM exposure, dose metrics, cellular uptake, cellular fate and transport are missing. As a consequence, accurate predictions about the adverse effects of ENM exposure are not possible and a regulatory framework for human health risk assessment of these materials has yet to be established. Given the scale at which the field of nanotechnology is expanding, and the immediate need to employ conventional toxicological approaches that are time and cost intensive, new strategies are needed to complete the safety assessment of currently available ENMs in a timely manner [6].

Toxicogenomics investigates global responses induced by toxic substances at the genome, transcriptome, proteome, and metabolome levels. Toxicogenomics has been used to evaluate the potential hazards of ENMs and to identify specific ENM properties that are responsible for their toxicity. For example, we recently employed gene expression profiling to demonstrate that nano-sized titanium dioxide (nano- $\mathrm{TiO}_{2}$ ) particles of varying sizes and surface properties induce pulmonary inflammation via the same mechanisms-of-action; however, the study showed that different nano- $\mathrm{TiO}_{2}$ particles vary in the magnitude of the inflammatory response induced in a property-dependent manner [7]. Similarly, Poulsen et al demonstrated that pulmonary transcriptional responses indicative of lung fibrosis varied for two carbon nanotubes (CNTs) of different length, width, and content of metal impurities [8]. Although informative, these analyses produced long lists of thousands of genes, proteins, and metabolites that were identified as differentially expressed in exposed versus control tissues, making it difficult to distinguish between genes that play a role in the observed biological response from those that represent spurious events. A greater challenge lies in the identification and discrimination of genes that define benign tissue defense mechanisms from those potentially important for the progression of adverse outcomes and diseases, as many disease-causing genes are often involved in host defense. In the case of ENMs, the identification of essential transcriptional signatures of diseases or pathogenesis early after exposure will not only provide insight into the underlying mechanisms of toxicities, but will also aid in developing rapid screening tests for prioritizing ENMs for further testing, identify disease producing ENMs, and enable the identification of markers of exposure and/or effect that can be potentially used for human biomonitoring and surveillance.

Nanotoxicology research has thus far not revealed toxicities or pathologies unique to ENMs, suggesting that the adverse outcomes of exposure to ENMs can be anticipated based on existing knowledge of the toxicity or pathology induced by analogous particles, chemicals, or substances [9]. Given the number of toxicogenomics studies that have investigated toxicant-induced lung diseases, in the present study we sought to define the critical gene expression fingerprints of lung events and diseases that are overrepresented in the lung transcriptional responses induced by ENMs. We conducted a meta-analysis of previously published gene expression microarray data from mouse lungs exposed to multiwalled CNTs (MWCNTs), carbon black (CB), and nano$\mathrm{TiO}_{2}$ of varying properties, and of publicly available gene expression microarray data of lung diseases induced by various exogenous agents including bleomycin, ovalbumin, TNFo, LPS, bacterial infection and welding fumes. Meta-analysis of the intersections of transcriptional changes induced by ENM and lung disease datasets were examined to identify signatures or features that are associated with ensuing lung pathology.

The study is a proof-of-principle and demonstrates the potential application of toxicogenomics data in identifying disease causing ENMs. By using publicly available lung injury models and ENMs that are known to induce lung events, we demonstrate how data derived from toxicogenomics as a stand-alone technique can inform potential disease potencies of ENMs that have not yet been extensively studied using conventional apical endpoints. The analysis was restricted to mouse models to minimize the loss of relevant biological information during the statistical normalization of cross-species data. The study analysis was also restricted to only those datasets that are readily available for download from public repositories and consisted of more than one dose in addition to controls.

\section{Methods}

Study selection

Table 1 summarizes the studies that were included in this analysis [7, 8, 10-19], including experimental 
Table $1 \mathrm{~A}$ list of the studies that were included in the meta-analysis and the experimental details

\begin{tabular}{|c|c|c|c|c|c|c|c|}
\hline Reference & Nanomaterial/Chemical & $\begin{array}{l}\text { Route of } \\
\text { exposure }\end{array}$ & Mouse strain & Dose & $\begin{array}{l}\text { Post-exposure } \\
\text { time point }\end{array}$ & Array platform & GSE \\
\hline $\begin{array}{l}\text { Poulsen et al. } \\
\text { (2015) [8] }\end{array}$ & Carbon nanotubes & Intratracheal & Adult C57BL/6 & $\begin{array}{l}\text { Single dose of } 18 \\
54,162 \mu \mathrm{g} / \text { mouse }\end{array}$ & $\begin{array}{l}1,3 \text {, and } \\
28 \text { days }\end{array}$ & $\begin{array}{l}\text { Agilent whole } \\
\text { genome }\end{array}$ & GSE35284 \\
\hline $\begin{array}{l}\text { Bourdon et al. } \\
\text { (2012) [10] }\end{array}$ & Carbon black & Intratracheal & Adult C57BL/6 & $\begin{array}{l}\text { Single dose of } 18 \\
54,162 \mu \mathrm{g} / \text { mouse }\end{array}$ & $\begin{array}{l}1,3 \text {, and } \\
28 \text { days }\end{array}$ & $\begin{array}{l}\text { Agilent whole } \\
\text { genome }\end{array}$ & GSE35193 \\
\hline $\begin{array}{l}\text { Halappanavar } \\
\text { et al. (2011) [13] }\end{array}$ & Nano titanium dioxide & Inhalation & Adult C57BL/6 & $\begin{array}{l}1 \mathrm{~h} \text { daily for } 11 \\
\text { consecutive days } \\
\text { to } 42.4 \mathrm{mg}\end{array}$ & 5 days & $\begin{array}{l}\text { Agilent whole } \\
\text { genome }\end{array}$ & GSE19487 \\
\hline $\begin{array}{l}\text { Guo et al. } \\
\text { (2012) [14] }\end{array}$ & Carbon nanotubes & $\begin{array}{l}\text { Pharyngeal } \\
\text { aspirations }\end{array}$ & Adult C57BL/6 & $\begin{array}{l}\text { Single dose of } 0, \\
10,20,40, \text { or } 80 \\
\mu \mathrm{g} \text { of } \mathrm{CNT} / \mathrm{mouse}\end{array}$ & $\begin{array}{l}1,7,28, \text { and } \\
56 \text { days }\end{array}$ & $\begin{array}{l}\text { Agilent whole } \\
\text { genome }\end{array}$ & GSE29042 \\
\hline $\begin{array}{l}\text { Reference not } \\
\text { available }\end{array}$ & Bleomycin & Intratracheal & $\begin{array}{l}\text { Adult Balb-c } \\
\text { and C57BL6 }\end{array}$ & $\begin{array}{l}\text { Single dose of } \\
0 \text { and } 1.5 \mathrm{U} / \mathrm{kg} \\
\text { body weight }\end{array}$ & $\begin{array}{l}24 \mathrm{~h}, 72 \mathrm{~h}, \\
10 \text { day and } \\
14 \text { days }\end{array}$ & $\begin{array}{l}\text { Affymetrix } \\
\text { murine genome }\end{array}$ & GSE485 \\
\hline $\begin{array}{l}\text { Erdely et al. } \\
\text { (2012) [15] }\end{array}$ & $\begin{array}{l}\text { Gas metal arc - stainless } \\
\text { steel welding fume }\end{array}$ & Inhalation & Adult C57BL6 & $\begin{array}{l}0 \text { or } 40 \mathrm{mg} / \mathrm{m}^{3} \\
3 \mathrm{~h} \text { daily for } 10 \\
\text { consecutive days }\end{array}$ & $\begin{array}{l}4 \mathrm{~h}, 14 \text { days, } \\
28 \text { days }\end{array}$ & $\begin{array}{l}\text { Illumina mouse } \\
\text { bead array }\end{array}$ & GSE34056 \\
\hline $\begin{array}{l}\text { Zeidler-Erderly } \\
\text { et al. (2010) [16] }\end{array}$ & $\begin{array}{l}\text { Gas metal arc-stainless } \\
\text { steel welding fume }\end{array}$ & $\begin{array}{l}\text { Pharyngeal } \\
\text { aspiration }\end{array}$ & $\begin{array}{l}\text { Adult } A / J \text { or } \\
\text { C57BL/6 J }\end{array}$ & $\begin{array}{l}\text { Four doses of } \\
85 \mathrm{mg} / \mathrm{kg}\end{array}$ & $\begin{array}{l}4 \text { and } \\
16 \text { weeks }\end{array}$ & $\begin{array}{l}\text { Illumina mouse } \\
\text { bead array }\end{array}$ & GSE20174 \\
\hline $\begin{array}{l}\text { Lewis et al. } \\
\text { (2008) [17] }\end{array}$ & $\begin{array}{l}12 \text { different lung disease model } \\
\text { datasets including bleomycin, } \\
\text { Th2 responses, and infection } \\
\text { models }\end{array}$ & $\begin{array}{l}\text { Differs with } \\
\text { the model of } \\
\text { lung disease }\end{array}$ & $\begin{array}{l}\text { Differs with } \\
\text { the model of } \\
\text { lung disease }\end{array}$ & $\begin{array}{l}\text { Differs with the } \\
\text { model of lung } \\
\text { disease }\end{array}$ & $\begin{array}{l}\text { Differs with } \\
\text { the model } \\
\text { of lung disease }\end{array}$ & $\begin{array}{l}\text { UCSF \&Mm } \\
\text { mouse oligo } \\
\text { array }\end{array}$ & GSE4231 \\
\hline $\begin{array}{l}\text { Halappanavar } \\
\text { et al. (2015) [7] }\end{array}$ & Nano titanium dioxide & Intratracheal & Adult C57BL/6 & $\begin{array}{l}\text { Single dose } \\
\text { of } 18,54,162 \text {, } \\
\text { or } 486 \\
\mu \mathrm{g} / \text { mouse }\end{array}$ & 1 and 28 days & $\begin{array}{l}\text { Agilent whole } \\
\text { genome }\end{array}$ & GSE60801 \\
\hline $\begin{array}{l}\text { Husain et al. } \\
\text { (2015) [19] }\end{array}$ & Carbon Black & Intratracheal & Adult C57BL/6 & $\begin{array}{l}\text { Single dose of } \\
162 \mu \mathrm{g} / \mathrm{mouse}\end{array}$ & $\begin{array}{l}3 \mathrm{~h}, \text { and } 2,3 \text {, } \\
4,5,14 \text {, and } \\
42 \text { days }\end{array}$ & $\begin{array}{l}\text { Agilent whole } \\
\text { genome }\end{array}$ & GSE68036 \\
\hline $\begin{array}{l}\text { Rahman et al. } \\
\text { (manuscript } \\
\text { in preparation) }\end{array}$ & Carbon nanotubes & Intratracheal & Adult C57BL/6 & $\begin{array}{l}4 \text { doses of } 128 \text { or } \\
47.5 \mu \mathrm{g} / \mathrm{mouse} \\
\text { per week }\end{array}$ & 60 days & $\begin{array}{l}\text { Agilent whole } \\
\text { genome }\end{array}$ & GSE65623 \\
\hline $\begin{array}{l}\text { Thomson et al. } \\
\text { (2012) [18] }\end{array}$ & $\begin{array}{l}\text { Lung-specific TNFa } \\
\text { over-expression }\end{array}$ & N/A & $\begin{array}{l}\text { Adult C57BL/6 } \\
\text { and transgenic } \\
\text { mice }\end{array}$ & N/A & N/A & $\begin{array}{l}\text { Agilent whole } \\
\text { genome }\end{array}$ & GSE11037 \\
\hline
\end{tabular}

details such as the nanomaterial/chemical, route of exposure, strain of mouse, dose, post-exposure time points investigated and microarray platform used. Since inhalation is an important route of exposure for ENMs in occupational settings, and since the pulmonary transcriptomic responses following exposure to some ENMs are fairly well characterized, studies that investigated the gene expression profiles of pulmonary responses to ENMs and lung disease models were used in the meta-analysis. The physico-chemical properties of the ENMs are summarized in Table 2. Data were obtained from the Gene Expression Omnibus (GEO) (http://www.ncbi.nlm.nih.gov/geo). The ultimate goal of this meta-analysis was to investigate the associations between gene expression profiles of lung tissue exposed to ENMs and of lung tissue from models of known pulmonary diseases.

\section{Data processing and normalization}

Due to differences in microarray platforms used across the chosen studies, all gene expression data were normalized using a common statistical method. The log2 transformation was applied to all signal intensity measurements. For two color microarray studies, the LOWESS normalization method [20], using the R statistical software environment [21] was applied. For studies using Affymetrix GeneChips ${ }^{\circ}$, the RMA normalization was applied using the justRMA function in the affy $\mathrm{R}$ package [22]. Quantile normalization was applied for studies using Illumina beadchip. This was done using the lumiN function in the lumi $R$ package [23].

Probes with technical replicates were then averaged using the median. The data for each study were then merged to their appropriate annotation files to obtain gene symbols. Probes with the same gene symbol were 
Table 2 The physico-chemical properties of the ENMs investigated in the studies listed in Table 1

\begin{tabular}{|c|c|c|c|c|c|}
\hline Reference & GSE & Name in study & Producer (particle name) & Size & $\operatorname{BET}\left(\mathrm{m}^{2} / \mathrm{g}\right)$ \\
\hline \multirow[t]{2}{*}{ Poulsen et al. (2015) [8] } & \multirow[t]{2}{*}{ GSE35284 } & $\mathrm{CNT}_{\text {small }}$ & Nanocyl (NC-7000) & $0.85 \pm 0.457 \mu \mathrm{m} \times 11 \pm 4.5 \mathrm{~nm}$ & 245.8 \\
\hline & & $\mathrm{CNT}_{\text {large }}$ & $\begin{array}{l}\text { IO-LE TECNanomaterials } \\
\text { (CP-0006-SG) }\end{array}$ & $4.05 \pm 2.40 \mu \mathrm{m} \times 67 \pm 2.40 \mathrm{~nm}$ & 14.6 \\
\hline Bourdon et al. (2012) [10] & GSE35193 & CBNPS & Evonik/Degussa (Printex 90) & $14 \mathrm{~nm}$ & 295-338 \\
\hline Halappanavar et al. (2011) [13] & GSE19487 & $\mathrm{NanoTiO}_{2}$ & Kemira (UV-titan L181) & $20 \mathrm{~nm}$ & 107.7 \\
\hline Guo et al. (2012) [14] & GSE29042 & MWCNT & Mitsui \& Company (MWCNT-7) & $3.86 \mu \mathrm{m} \times 49 \pm 13.4 \mathrm{~nm}$ & $\begin{array}{l}\text { not listed in } \\
\text { study }\end{array}$ \\
\hline \multirow[t]{5}{*}{ Halappanavar et al. (2015) [7] } & \multirow[t]{5}{*}{ GSE60801 } & $\mathrm{TiO}_{2} \mathrm{NP}^{10.5}$ & NanoAmor (NRCWE-030) & $10.5 \mathrm{~nm}$ & 139.1 \\
\hline & & $\mathrm{TiO}_{2} \mathrm{NP}^{38}$ & Nabond (NRCWE-025) & 38 nm & 28.2 \\
\hline & & $\mathrm{TiO}_{2} \mathrm{NP}^{10}$ & NanoAmor (NRCWE-001) & $10 \mathrm{~nm}$ & 99 \\
\hline & & $\mathrm{TiO}_{2} \mathrm{NP}^{10+}$ & NanoAmor (NRCWE-002) & $10 \mathrm{~nm}$ & 84 \\
\hline & & $\mathrm{TiO}_{2} \mathrm{NP}^{20.6}$ & Kemira (UV-Titan L181) & $20.6 \mathrm{~nm}$ & 107.7 \\
\hline Husain et al. (2015) [19] & GSE68036 & CBNPs & Evonik/Degussa (Printex 90) & $14 \mathrm{~nm}$ & 295-338 \\
\hline \multirow[t]{2}{*}{ Rahman et al. (manuscript in preparation) } & \multirow[t]{2}{*}{ GSE65623 } & Mitsui XNRi-7 & Mitsui \& Company (NRCWE-006) & $5.7 \pm 0.49 \mu \mathrm{m} \times 74(29-173) \mathrm{nm}$ & 26 \\
\hline & & CNT 401 & OECD WPMNM (NM-401) & $4.0 \pm 0.37 \mu \mathrm{m} \times 67(24-138) \mathrm{nm}$ & 18 \\
\hline
\end{tabular}

then averaged using the median. Experimental conditions with biological replicates were averaged using the median. The data were further normalized by subtracting the median average of the appropriate control samples resulting in the $\log 2$ fold change for each experimental condition. The control samples were then removed from the data set. All studies were then merged together using the gene symbol for data analysis.

A total of 2334 gene symbols were in common across all platforms with 190 experimental conditions relative to controls. The resulting data matrix consisting of gene symbols were filtered based on the number of experimental conditions exceeding a $\log 2$ (1.5 fold) cut-off. Although the use of fold change ranking in conjunction with a flexible (non-stringent) p-value threshold is suggested in order to generate reproducible differentially expressed gene lists [24], no numeric values as fold change or p-value cut-offs have been specifically prescribed. Using a pre-determined stringent cut-off for fold change to identify differentially expressed genes, especially in an experiment where the objective is to determine the effects following exposures to ENMs of varying potency and across several doses (including low doses where not many changes are expected), may compromise sensitivity and miss some biologically relevant genes that have low fold changes. For this reason, we have used the fold change of 1.5. Furthermore, the filtering helped remove non-informative genes that could distort correlations between experimental conditions. Gene symbols that had more than 5 experimental conditions that exceeded this cut-off (in absolute value) were retained for hierarchical cluster analysis, which resulted in 945 gene symbols.

\section{Dendrogram analysis}

Hierarchical clustering is a statistical technique that groups experimental conditions based on distances. Hierarchical cluster analysis was conducted on normalized expression levels of the 945 gene symbols identified above. Here, the 1-Pearson correlation dissimilarity metric was used. The average linkage function, which determines how distances between sets of observations are calculated, was used and the analysis was conducted using the $\mathrm{R}$ software package.

\section{Gene Ontology Analysis}

A shortlist of differentially expressed genes (DEGs) that showed differential expression in at least $50 \%$ of the experimental conditions within the respective cluster was used in the analysis, so that only genes that are involved in the majority of experimental conditions were examined. To determine the biological relevance of the DEGs identified in the disease clusters, an analysis of the gene ontologies (GOs) enriched within the shortlisted genes of each cluster was performed. This analysis used the gene ontology consortium database, and was performed using the Cytoscape (Cytoscape Consortium) software app ClueGo (Laboratory of Integrative Cancer Immunology, Paris, France) [25, 26]. The enrichment analysis used gene associations based only on experimental evidence. GOs were included if they had a minimum of 3 genes expressed and if a minimum of $4 \%$ of the $\mathrm{GO}$ was represented. To reduce the redundant GOs, GoFusion was enabled in the ClueGo software, and GOs were collapsed back to parent ontologies if all of the DEGs from the Parent and child GOs were the same. For ball and 
stick diagrams, a $50 \%$ overlap of DEGs was used as the threshold for grouping of the GOs.

\section{Upstream Regulator analysis}

Ingenuity Pathway Analysis (IPA) software (Qiagen Silicon Valley) was used to determine the upstream regulators of gene expression that might contribute to the gene expression profiles identified in the disease clusters. Specifically, the upstream regulator analysis tool was used, and only gene products, miRNA, and proteins were selected. Only upstream regulators with z-scores of 3 or more and with $\mathrm{p}<0.001$ were included.

\section{Fibrosis associated genes}

The gene list fibrosis of the lung from the IPA archives was used to identify genes associated with pulmonary fibrosis. Tables and heat maps were constructed using this list as a reference.

\section{Results \\ Comparison of transcriptomic datasets of ENM exposure versus models of lung disease}

To understand if gene expression signatures obtained from the lungs of mice exposed to nano $\mathrm{TiO}_{2}, \mathrm{CB}$ or MWCNTs may be associated with specific lung diseases, a meta-analysis was performed that included 12 studies that investigated lung injury or lung diseases and ENMinduced pulmonary responses (Table 1). A final data set consisted of $\sim 700$ individual microarray hybridizations representing 137 experimental conditions. Due to differences in microarray platforms used to collect the gene expression data included in this meta-analysis, only those genes that were consistently found on all of the platforms were used to derive a list of 2334. DEGs (Additional file 1: Table S1). A gene showing expression changes $>1.5$ relative to matched controls in more than 5 of the 137 total experimental conditions was considered to be significant and was included in the metaanalysis. Through this criterion, a total of 954 DEGs were derived. Hierarchical clustering of the 954 genes was conducted to visualize the relationship between the different experimental datasets (Fig. 1).

The key findings of this analysis, which are summarized in Fig. 1, reveal the following: 1) there were transcriptional features distinct to the response induced by bacterial infection, bleomycin induced lung injury, $\mathrm{T}$ helper type 2 lymphocytes (Th2)-mediated allergic response and ENMs; 2) all experimental samples exposed to nanoTiO ${ }_{2}$ clustered separately (Fig. 1 , nanoTiO ${ }_{2}$ cluster) from the MWCNT-exposed samples (Fig. 1, MWCNT cluster); and, 3) only MWCNT datasets clustered with lung disease models (Fig. 1, MWCNT cluster). Within the MWCNT cluster, two sub-clusters were identified: 1) the cluster colored in pink, which included datasets from the bleomycin-induced injury and bacterial infection models; and 2) the blue cluster which consisted of the dataset from the ovalbumin sensitization model characteristic of a Th2 response. Both the pink and blue clusters contained experimental samples from studies of MWCNTs with different physic-chemical properties and included a range of doses. The clustering of the MWCNT-exposed samples within these subclusters was mainly associated with different postexposure time points at which the analysis was conducted. The MWCNT data sets in the pink cluster alongside the bleomycin/bacterial studies were primarily from the $24 \mathrm{~h}$ post-exposure time point; whereas, those found in the blue cluster (together with Th2 response studies) were predominantly from the 14, 28 and 56 days post-exposure time points. A 3 day post-MWCNT exposure time point was also included in the metaanalysis. These datasets did not show distinct clusters and were scattered across the MWCNT cluster, with 4 of the 6 experimental groups clustering in pink with the bleomycin/bacteria models. The analysis suggests that the initial response to MWCNT administration is similar to lung responses observed following bacterial challenge or following exposure to a damaging substance like bleomycin; whereas, later responses to MWCNT are similar to Th2 response induced following exposure to allergens. Th2-induced gene expression of several cytokines, chemokines and growth factors is known to play a critical role in the progression of lung fibrosis [27], a lung disease observed at 14 or 28 days following exposures to MWCNTs [28]. Examining the genes that drive this clustering may provide insight into the biological processes engaged in these two distinct phases of the pulmonary responses to MWCNTs.

In general, the clusters showed clear associations between datasets from MWCNT-exposed lungs and lung disease models; however, some individual samples from the bleomycin injury, bacterial infection, nano $\mathrm{TiO}_{2}$, and arc-stainless steel studies clustered under a separate branch at the distal end of the MWCNT cluster. The clustering of these samples may reflect differences in the individual animal responses. Similarly, several CB and nanoTiO $\mathrm{T}_{2}$ groups including the only inhalation study describing responses to inhaled nanoTiO $\mathrm{Ti}_{2}$ consisting of single dose and single post-exposure time point were clustered together in between the pink and the blue cluster. Although it is tempting to speculate that the route of exposure (inhalation vs instillation) may have something to do with this unique clustering in the case of the nanoTiO 2 inhalation study group, detailed analysis of DEGs in the cluster did not reveal such unique features. More studies systematically investigating the responses following exposure to particles delivered via two different administration routes are required. 


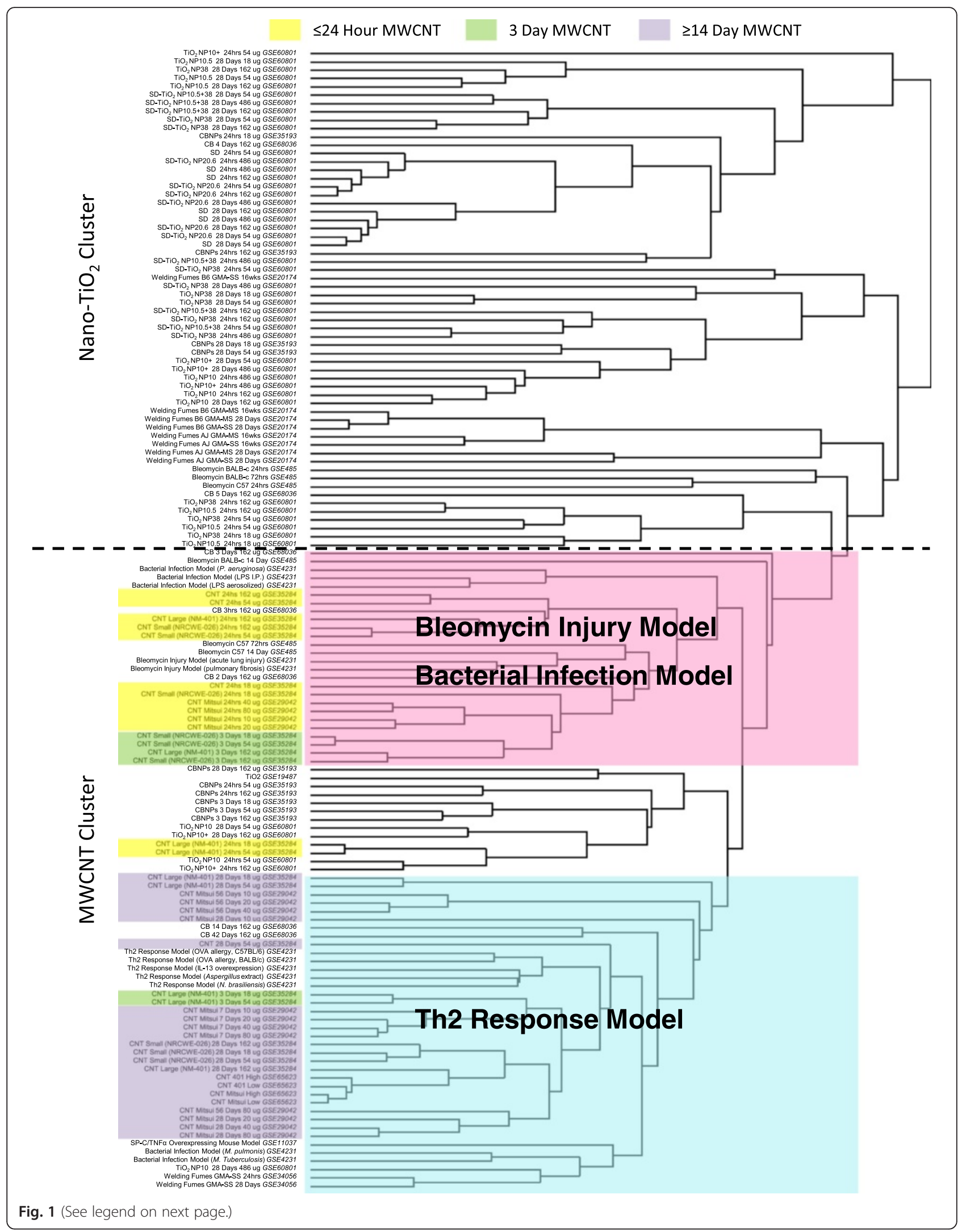


(See figure on previous page.)

Fig. $1 \mathrm{NanOTIO}_{2}$ and MWCNTs clustered separately, and MWCNTs were further differentiated by the post-exposure time period. Hierarchical clustering was used to visualize the differential expression of 2334 common genes across the microarray platforms used in this study and across 137 different experimental conditions from 12 studies. The figure depicts the clustering of individual arrays performed on RNA isolated from murine lung tissue within each respective study. Two distinct clusters were identified, with nanoTiO 2 arrays and MWCNT arrays clustering separately. The MWCNT cluster could be further divided into two sub-clusters: (1) arrays from MWCNT exposure models were correlated with those from bacteria and bleomycin exposure models (pink); and (2) expression profiles from MWCNT exposure models were correlated with arrays from a Th2 model (blue). Other nanomaterial exposure models did not cluster in notable patterns

Additionally, some CB experimental groups were observed in the pink (bleomycin/bacteria) and the blue (Th2 response) sub-clusters. These findings imply that transcriptional responses to carbon-based nanoparticles $(\mathrm{CB}$ and MWCNTs) may share some similarities; however, we caution that the results of the CB-exposed samples are inconsistent. Transcriptional response to stainless steel also clustered separately. The closest nodes to stainless steel were acute exposure to bleomycin and acute exposures to nanoTiO ${ }_{2}$. Since only MWCNT datasets showed clear association with the lung disease models, the analysis described below focused on the pink and blue subclusters.

\section{GO functional analysis of DEGs intersecting bacteria/ bleomycin (pink) and Th2 response (blue) clusters}

It is expected that the essential features of any biological response, including a disease phenotype, are overrepresented in the affected/exposed tissues relative to the unaffected/unexposed control tissues. To identify these transcriptional features we explored transcriptional similarities of the lung disease models and MWCNTinduced pulmonary responses, by investigating the genes in common with the various experimental conditions that made up the pink and blue sub-clusters. A shortlist of upregulated and downregulated genes was generated for each intersection, which consisted of genes that were significantly altered in at least $50 \%$ of the datasets within that specific cluster. Gene expression fold changes were used to generate a heat map for each cluster (Figs. 2 and 3). The shortlist of genes in the bleomycin/bacterial cluster (pink) consisted of 79 upregulated and 21 downregulated genes (Fig. 2). The Th2 response cluster (blue) consisted of 53 upregulated and 3 downregulated genes (Fig. 3). There was a high degree of overlap in genes between the different biological functions identified.

In order to investigate the type of biological processes perturbed by the DEGs that are common in either the pink bleomycin/bacteria or the blue Th2 response subclusters, the short list of genes was analyzed using the Cytoscape app, ClueGo. This analysis takes into account the experimentally curated gene ontologies specific to biological processes. Because the pink cluster consists of acute post exposure time points and the blue cluster consists of longer post-exposure time points, this analysis effectively differentiates biological processes engaged in the early and late phases of the response to MWCNT, in addition to highlighting the processes that overlap with lung disease models.

\section{Biological processes/functions perturbed in bacteria/ bleomycin cluster}

The short list of DEGs from the pink cluster was enriched in host defense GOs and the response to specific stimuli (Fig. 2). Specifically, defense response (GO:0006952), which indicates that mechanisms involved in host-defense against invasive agents were engaged, and response to wounding (GO:0009611), implying that MWCNTs are damaging to the lung environment at early time points, were enriched. The other enriched biological processes included response to organic substance (GO:0010033) and response to oxygen containing compound (GO:1901700), suggesting a commonality between the response to this broad group of stimuli and MWCNTs. Five genes from the shortlist, Ccl2, Hif1a, Myd88, Socs3, and Tnf, were common to all of these GOs. In addition, regulation of myoblast differentiation (GO:0045661) was enriched, but its involvement in the pulmonary response to MWCNT is not clear. Forty-six of the upregulated genes were not associated with any enriched GOs in this analysis. Enrichment analysis of the downregulated genes identified blood circulation (GO:0008015), chemical homeostasis (GO:0048878), and stem cell development (GO:0048864) processes to be altered, which indicates that homeostatic processes like the circulation of blood and developmental processes may be disrupted in the lungs by acute MWCNT exposure as it is in bacterial infection and bleomycin exposure. Twelve of the downregulated genes could not be associated with any enriched GO.

\section{Biological processes/functions perturbed in Th2 response cluster}

Similar to the pink cluster, the enriched GOs in the blue cluster also included in host-defense mechanisms (Fig. 3), such as defense response (GO:0006952), inflammatory response (GO:0006954), granulocyte chemotaxis (GO:0071621), regulation of leukocyte mediated immunity (GO:0002703), and positive regulation of endocytosis (GO:0045807). GOs related to a broad range of immune functions were also enriched, including response to other 


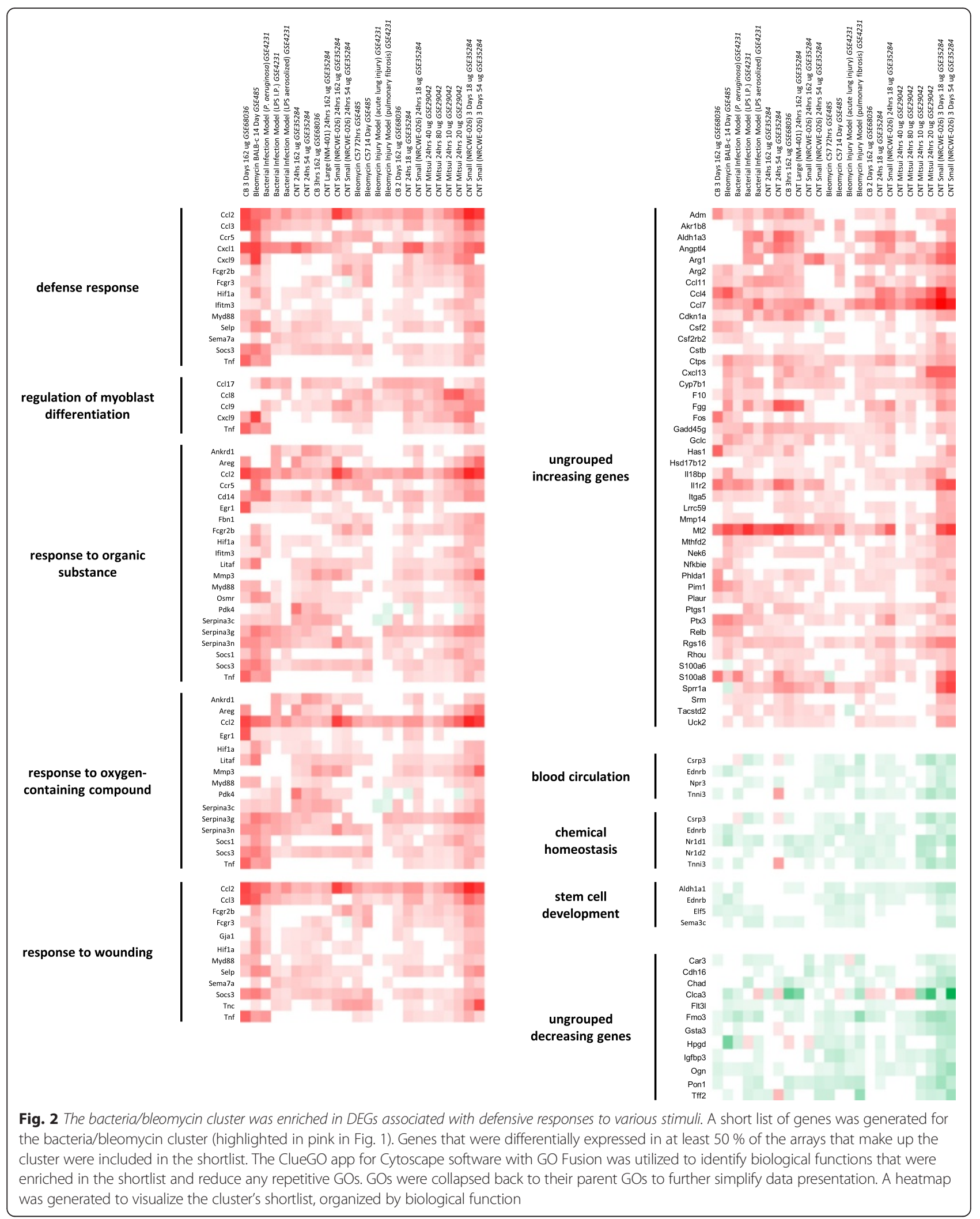




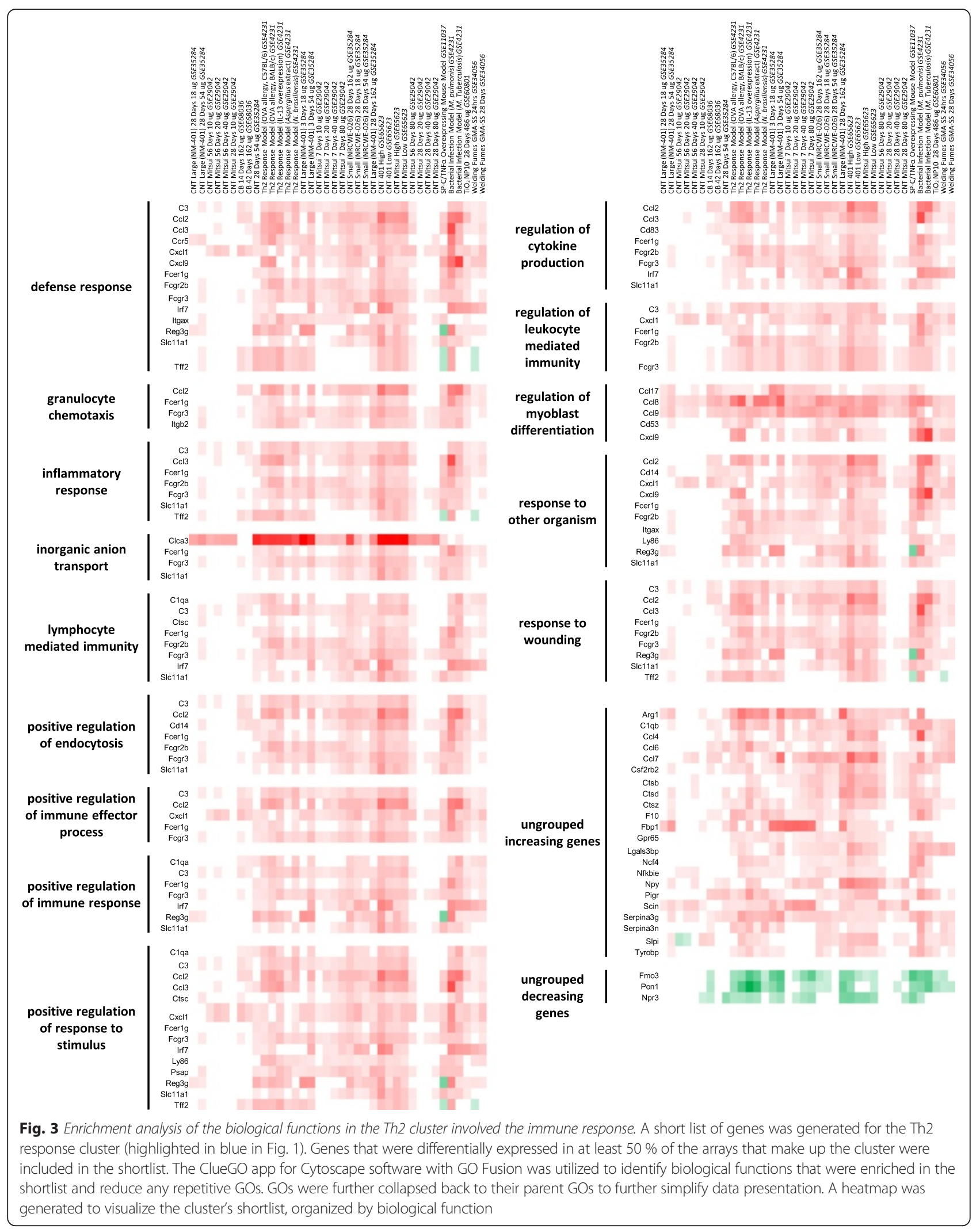


organism (GO:0051707), positive regulation of immune response (GO:0050778), and regulation of cytokine production (GO:0001817). In addition, GOs related to the adaptive immune response such as lymphocyte mediated immunity (GO:0002449) were also enriched. Adaptive immunity and lymphocyte function are key components that characterize the Th2 response and this GO represents an important overlap between MWCNT exposure and the Th2 response model. Upregulated genes associated with these immune response GOs included C1qa, C3, Ccl2, Ccl3, Cxcl1, Cxcl9, Fcer1g, Fcgr2b, Fcgr3, Irf7, and Slc11a1. The inorganic anion transport (GO:0015698) and regulation of myoblast differentiation (GO:0045661) ontologies were also enriched in this analysis, although their relevance to the response to MWCNT is less intuitive. The enrichment of positive regulation of response to stimulus (GO:0048584) and response to wounding (GO:0009611) was also observed, which suggested that damage to the pulmonary environment is activating repair mechanisms at early and late time points; however, a large number of adaptive immune mechanisms are engaged at later phases of the response to MWCNTs. Only 3 genes were down regulated in this shortlist and enrichment analysis of such a small list did not produce any meaningful results.

Visual inspection of the heat maps (Figs. 2 and 3) reveals a pattern that is consistent with a dose response in gene expression changes at later post-MWCNT exposure time points. Although the pink cluster showed similar transcription levels across all of the arrays (Fig. 2), gene expression patterns in the blue cluster revealed time and dose-dependence (Fig. 3). Specifically, samples exposed to lower doses $(40 \mu \mathrm{g} /$ mouse or less) MWCNTs analyzed at 56 days post-exposure showed less similarity in expression changes with the Th2 response model. In contrast, mice exposed to more than $40 \mu \mathrm{g} /$ mouse showed a higher degree of similarity in transcriptional profiles to the Th2 response models at 3, 7 and 28 days post-exposure time points. Thus, there was a dose and time dependency in association of MWCNT samples with disease models.

\section{Analysis of upstream regulators controlling the perturbed processes in both bacteria/bleomycin and Th2 response clusters}

IPA was used to identify the upstream transcriptional regulators potentially controlling the observed gene expression changes in the pink and blue clusters. Upstream regulators showing a Z-score above 2.0 are shown in Fig. 4a. Interestingly, a number of genes known to regulate inflammatory processes (Tnf, Ifng, and $I l 1 b$ ), and genes involved in regulating cell proliferation and growth ( $T g f b 1$ and Csf2), had the highest Z-scores for both sub-clusters. This suggests that the two clusters are regulated by similar processes. A Venn analysis of the upregulated genes in the shortlists from both sub-clusters confirmed a total of 22 overlapping genes that were upregulated in both clusters (Fig. 4b). No such analysis could be conducted for the down regulated genes, as the blue cluster shortlist contained only 3 down regulated DEGs. Further analysis of the 22 overlapping genes using ClueGo/Clupedia network analysis showed that these genes are mainly associated with recruitment of leukocytes and were grouped under positive regulation of transport (GO:0051050), leukocyte chemotaxis (GO:0030595), myeloid leukocyte migration (GO:0097529), and regulation of cytokine production (GO:0001817) (Fig. 4c). The Ccl2, Ccl3, Fcgr2b, and Fcgr3 genes were common to all GO categories. Collectively, this analysis suggests that inflammation and inflammation related genes govern the responses observed in the two sub-clusters (pink and blue). These results suggest that both phases of the response to MWCNT are driven by inflammatory mediators despite distinct clustering of the early and late phases of the MWCNT with different lung disease models, and that several of these mediators are continually expressed.

\section{Gene expression changes associated with lung fibrosis}

The lung injury models including bleomycin, Th2 response-mediated allergy, and bacterial infection are all known to cause lung fibrosis [27]. Similarly, exposure to different variants of MWCNTs induces pulmonary fibrosis in several studies $[28,29]$. In fact, lung fibrosis is a well-characterized adverse pulmonary outcome induced by MWCNTs. Thus, the short lists of intersecting genes were examined for their direct association with lung fibrosis.

Lung fibrosis has been extensively studied and several of the genes involved in this process have been identified. Using the IPA pathway and network database, a list of 105 genes associated with fibrosis of the lung network was created. Next, the gene lists from the pink and blue clusters, as well as genes identified in the upstream regulator analysis, were overlaid onto the IPA fibrosis network gene list. This analysis identified 23 specific genes associated with both clusters that are directly relevant to the progression of lung fibrosis (Fig. 5a). Of particular interest were $\mathrm{Arg1}, \mathrm{C3}$, and $\mathrm{Ccl17}$, genes which were increased at 7, 28, and 56 days post-exposure time points in MWCNT studies, when fibrosis is observed histologically in this model [8]. Interestingly, Arg1, C3, and Ccl17 are all genes considered to be biomarkers of alternatively activated macrophages, a cell type that requires Th2regulated cytokines for its differentiation, and that also have been implicated in the progression of pulmonary fibrosis [30, 31].

Meta-analysis of the gene expression data derived from various studies identified MWCNTs as potential fibrosis-inducing substances that could possibly mediate 


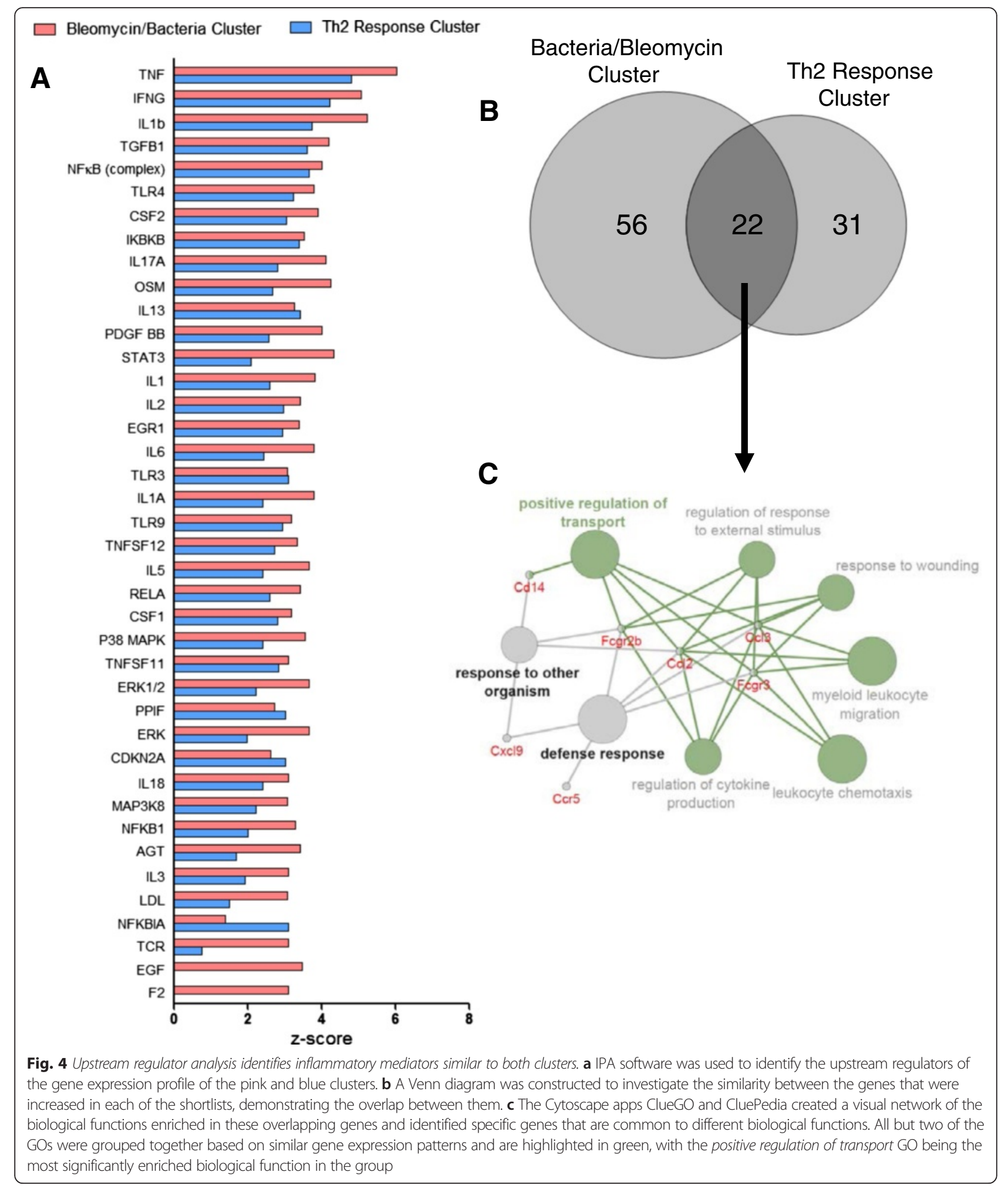

their fibrotic response via the Th2-mediated signaling. However, given the variability in the study designs, doses used and statistical normalization processes employed, the genes in the cluster shortlists would not be expected to include all of the potential pro-fibrotic genes induced by MWCNT exposure. Although, the cluster analysis 


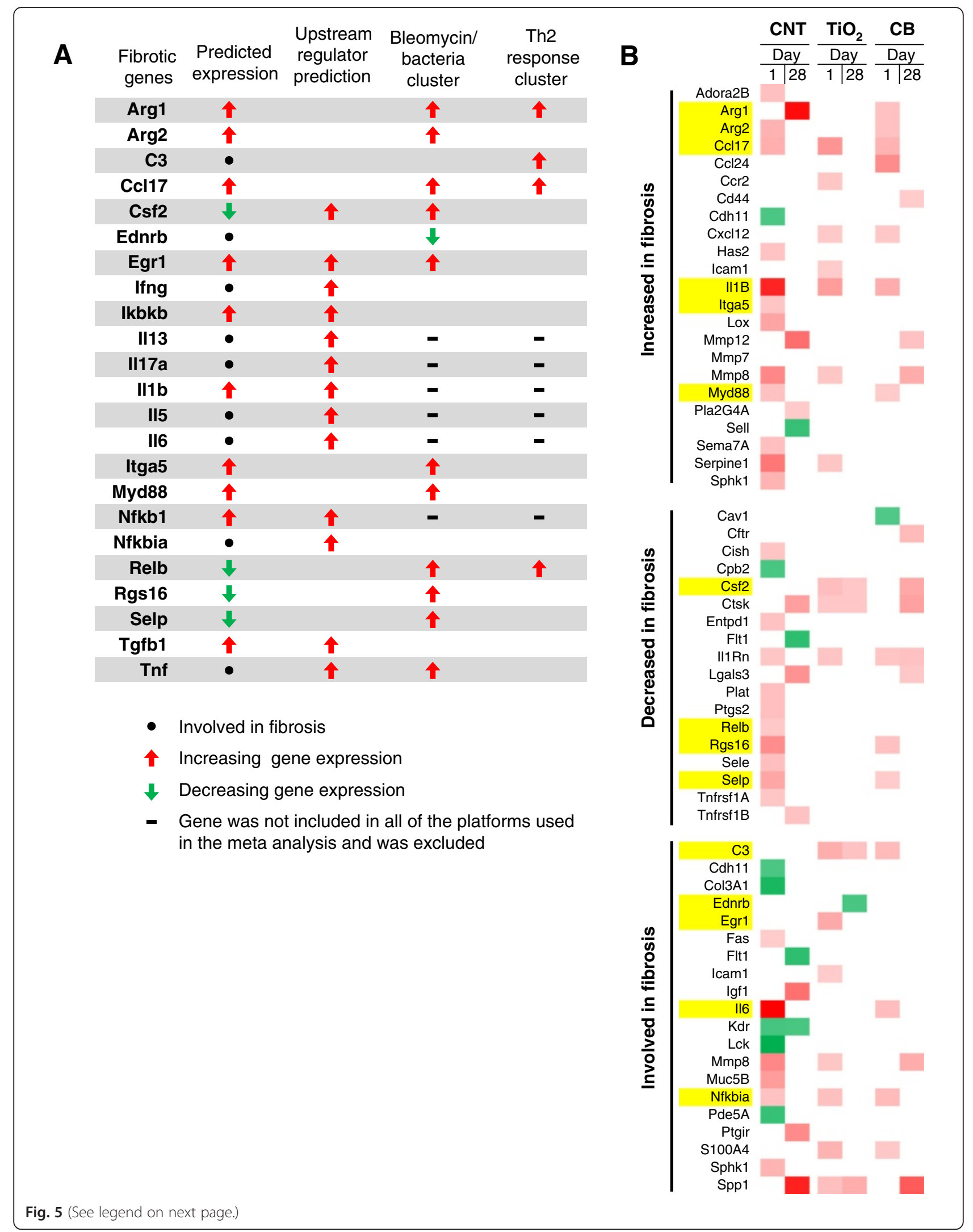


(See figure on previous page.)

Fig. 5 The MWCNT sub-clusters include pro-fibrotic genes that can differentiate MWCNT from less fibrotic nanomaterials. a A list of fibrosis genes was obtained from the IPA database and the overlapping genes shortlisted in the pink and blue clusters, as well as the genes identified as upstream regulators of the pink and blue cluster shortlists, are indicated. $\mathbf{b}$ The fibrosis gene list from IPA was also applied to gene shortlists from $\mathrm{CNT}_{1} \mathrm{TiO}_{2}$, and $\mathrm{CB}$ datasets that were included in this meta-analysis with the same dose and time points to show the differences in gene expression between MWCNTs and other less fibrotic nanomaterials. Genes from Fig. 5a are highlighted in yellow

may be used to identify a portion of the biological response that is involved in fibrotic pathogenesis, it is likely that additional genes are involved. As such, several pro-fibrotic genes that may have been altered in response to nano $\mathrm{TiO}_{2}$ and $\mathrm{CB}$ exposures may not have been measurably altered in this study, this likely resulted in differential grouping of these substances.

To investigate this hypothesis, the list of IPA's fibrosis of the lung disease network genes was overlaid onto the day 1 and day 28 DEG lists of mouse lungs exposed to $162 \mu \mathrm{g}$ of MWCNTs, nanoTiO $\mathrm{Ti}_{2}$, or CB (from studies that were included in the meta-analysis) $[8,10,11]$. These genes were divided into three groups depending on whether the genes are expected to increase fibrosis, decrease fibrosis, or if the direction of change is uncertain (Fig. 5b). The genes highlighted in yellow were the ones identified through the cluster analysis (Fig. 5a). This analysis revealed additional genes from the MWCNT datasets associated with fibrosis but not many genes from the nanoTiO ${ }_{2}$ and CB studies. This expanded list of genes included Mmp12, Spp1, Pla2g4a, Igf1, and Ptgir which were expressed at greater levels in MWCNT exposed lungs at 28 days post-exposure.

\section{Discussion}

Microarray technology has been extensively used to investigate the relationship between gene expression profiles and molecular mechanisms underlying diseases. In this study, we compared pulmonary gene expression profiles derived from mice exposed to different ENMs to those induced by chemical substances or pathogens causing lung diseases. Our meta-analysis demonstrates a feasible approach for the application of global gene expression profiling to identify the potential of ENMs to cause pulmonary pathogenesis. By using a variety of lung models of inflammatory diseases, we identified common transcriptional changes between lung diseases and ENMinduced lung responses. This allowed us to bin MWCNTs as potentially disease-causing ENMs separately from the nanoTiO ${ }_{2}$ and $C B$, as ENMs not associated with lung disease at the concentrations and time points examined in this study. This work also revealed potential mechanisms by which MWCNTs induce lung fibrosis, and identified a suite of marker genes that may serve as predictors of lung fibrosis.
Several studies argue that inflammation does not play a role in pulmonary fibrosis in general $[32,33]$. This is mainly due to the lack of an influx of inflammatory cells observed in patients presenting with lung pathology in parallel with the lack of efficacy of immunosuppressive drugs in fibrosis patients $[34,35]$. In line with this argument, in MWCNT-exposed mice presenting with the fibrotic phenotype (studies included in the analyses), BAL cellular influx recedes (but does not completely reverse) with time and fibrotic lesions do not present inflammatory characteristics [8]. However, the gene expression data shown here suggest otherwise and provide clues as to how the process of inflammation may participate in the fibrotic pathology. The meta-analysis showed that pulmonary gene expression signatures induced by MWCNTs were similar to patterns of bacterial, bleomycin, and Th2-mediated allergic response models that induce robust pulmonary inflammation, and revealed altered gene expression of a large suite of inflammatory cytokines and chemokines across the acute and sub chronic post-exposure time points. The results also showed that the upstream regulators governing the altered gene expression profiles involved the transcriptional factors responsible for regulating inflammation.

In addition to cytokines, genes involved in alternatively activated (M2) macrophages resulting from polarized Tcell response (eg. Arg1, C3, and Ccl17) were upregulated in MWCNT-exposed lung datasets. M1 and M2 macrophage types are involved in mediating pulmonary inflammatory responses at different stages of the response [36]. M1 macrophages kill invading pathogens or injured cells and produce pro-inflammatory cytokines [36]. In contrast, activated M2 macrophages secrete anti-inflammatory cytokines, regulate M1-mediated inflammatory responses, aid in clearance of cellular debris, and promote angiogenesis, tissue remodeling, and repair [36]. Upregulation of Arg1, C3, and Ccl17 potentially results in the activation of the M2 phenotype, and simply reflects the transition to a different functional state (from innate immune to adaptive response) in cells battling persistent injury inflicted by residual MWCNTs. This was also evident by the temporal nature of the association between the MWCNT-induced lung responses and disease models; early responses (24 h, 3days) had transcriptional profiles that were consistent with bacterial- or bleomycin-induced injury responses, and the later 
responses (28days) suggested an association with Th2mediated response, reflecting a transition from early innate immune response to later adaptive immune responses, respectively. Thus, profuse inflammation, continuing injury, and tipping of the delicate balance between pro- and anti-inflammatory mediators results in the activation of alternate cell types and secretion of pro-fibrotic molecules which creates a microenvironment conducive for the development of lung fibrosis. The inflammatory process has been implicated in lung fibrosis induced by crystalline silica and asbestos [37], both of which are shown to accumulate in alveolar macrophages resulting in the activation of an inflammatory cascade that eventually results in lung fibrosis. MWCNTs are suggested to behave like asbestos due to their fiber like structures [38]. Collectively, these results suggest an important role for inflammation in ensuing lung fibrosis induced by MWCNTs.

Although nanoTiO ${ }_{2}$ and $\mathrm{CB}$ exposure also induce lung inflammation and alter the expression of several proinflammatory genes [39], mice exposed to these ENMs did not show a clear association with the disease models. There are many differences in the characteristics of inflammation produced by nano $\mathrm{TiO}_{2}$ and $\mathrm{CB}$, including: 1) $\mathrm{CB} /$ nanoTiO $\mathrm{T}_{2}$ exposure causes significantly less inflammation than MWCNT in mice exposed at similar exposure doses and sampling regimens; 2) nanoTiO ${ }_{2}$ and $\mathrm{CB}$ induced inflammation is predominantly neutrophilic; whereas, MWCNT induced inflammation involves multiple cell types; 3 ) with the exception of the highest doses examined, BAL cellular influx significantly declines 28days post-exposure following nano $\mathrm{TiO}_{2}$ and $\mathrm{CB}$ exposure, it is less reduced in mice exposed to MWCNT; 4) gene expression patterns in nanoTiO ${ }_{2}$ or $\mathrm{CB}$ exposed samples are mainly associated with acute innate response; and, 5) the magnitude of expression change for any given gene is relatively lower for nanoTiO ${ }_{2}$ or $\mathrm{CB}$ exposed samples compared with MWCNTs and the majority of these changes are reversed by 28 days post-exposure $[8,10,11]$. Although some CB samples were interspersed with the disease models, the response varied within specific experimental conditions and lacked consistency. Neither nanoTiO ${ }_{2}$ nor $\mathrm{CB}$ have been shown to induce lung fibrosis at the doses or time points analyzed in this study.

The other interesting observation, though subtle, was that the experimental conditions from the welding fumes study clustered differently in a manner that seemed to depend on their lung administration methods (aspiration versus inhalation). However, the two studies were conducted at different times and varied in the experimental design including the doses administered. In the context of ENMs, it can be expected that lung responses to ENMs introduced via inhalation, aspiration or intratracheal deposition may be different because of the differences in the deposited dose and ENM distribution in lungs. However, we have previously shown that lung inflammatory responses to surface-coated $\mathrm{TiO}_{2} \mathrm{NPs}$ deposited in mouse lungs via intratracheal instillation or inhalation are similar [11]. Jackson et al did not observe differences in the lung distribution or effects in mice exposed to carbon black particles via intratracheal instillation or inhalation [40]. Future studies directly comparing the pulmonary toxicogenomics responses from mice exposed to ENMs via inhalation or other lung administration routes are warranted. Currently, such a comparison is not possible as lung toxicogenomics data from inhalation models are not available.

Other groups have employed global gene expression profiling to identify signatures predictive of lung cancer for ENMs. Pacurari et al. showed changes in the expression of a select set of lung cancer biomarker genes following exposure to MWCNTs and suggested a link between MWCNT-induced lung inflammation, fibrosis, and cancer [41]. A follow up study by Guo et al. conducted genome-wide gene expression profiling of MWCNT-exposed mouse lungs and compared the gene expression profiles to human lungs derived from lung cancer patients to predict lung cancer progression by correlating mouse gene expression data with expression in patient lungs [14]. A recent study by Sargent et al showed that Mitsui-7, a rigid, rod-like fiber acts as a cancer promoter; however, there is no current evidence to support the occurrence of lung cancer following exposure to all types of MWCNTs [42].

In addition to lung cancer and fibrosis, MWCNTs may also contribute to other lung diseases, though little data exist to support this possibility. Consistent with the findings of our meta-analysis demonstrating similarities in the transcriptional response of MWCNTexposed mice and Th2 disease models, MWCNT have been shown to stimulate and exacerbate allergic airways [28, 43-45]. These animal models demonstrate an increase in allergic inflammation, mucus hyperplasia, and fibrotic airway when MWCNT are administered along with an allergen or surrogate allergen. These observations from allergy models highlight an important consideration for the toxic properties of MWCNTs as these materials may play a synergistic role with other lung pathologies. With respect to pulmonary infections, MWCNT administration is associated with increased infectivity of the influenza virus, implying a suppression of certain host defense mechanisms after MWCNT exposure [46]. Increased mucus production can exacerbate diseases with pathologies that include airway obstruction by further decreasing airflow. MWCNTs have been shown to increase mucus production [47], which has the potential to exacerbate asthma and Chronic Obstructive Pulmonary Disease. The current analysis characterizes the biological response to 


\section{Early Phase \\ $0 \rightarrow 24 \mathrm{hrs}$ \\ Clustered with: \\ - Bleomycin models \\ - Bacteria models \\ GOs in cluster: \\ - Response to organic substance \\ - Response to oxygen-containing compound \\ - Response to wounding \\ - Regulation of myoblast differentiation}

\section{Intermediate}

Phase

$1 \rightarrow 7$ days

- Establishing chronic inflammation

\section{Late Phase}

$\geq 7$ days

Clustered with:

- Th2 response models

GOs in cluster:

- Response to wounding

- Inflammatory response

- Lymphocyte mediated immunity

- Regulation of cytokine production

- Positive regulation of immune response

- Response to other organism

- Defense response

- Regulation of myoblast differentiation

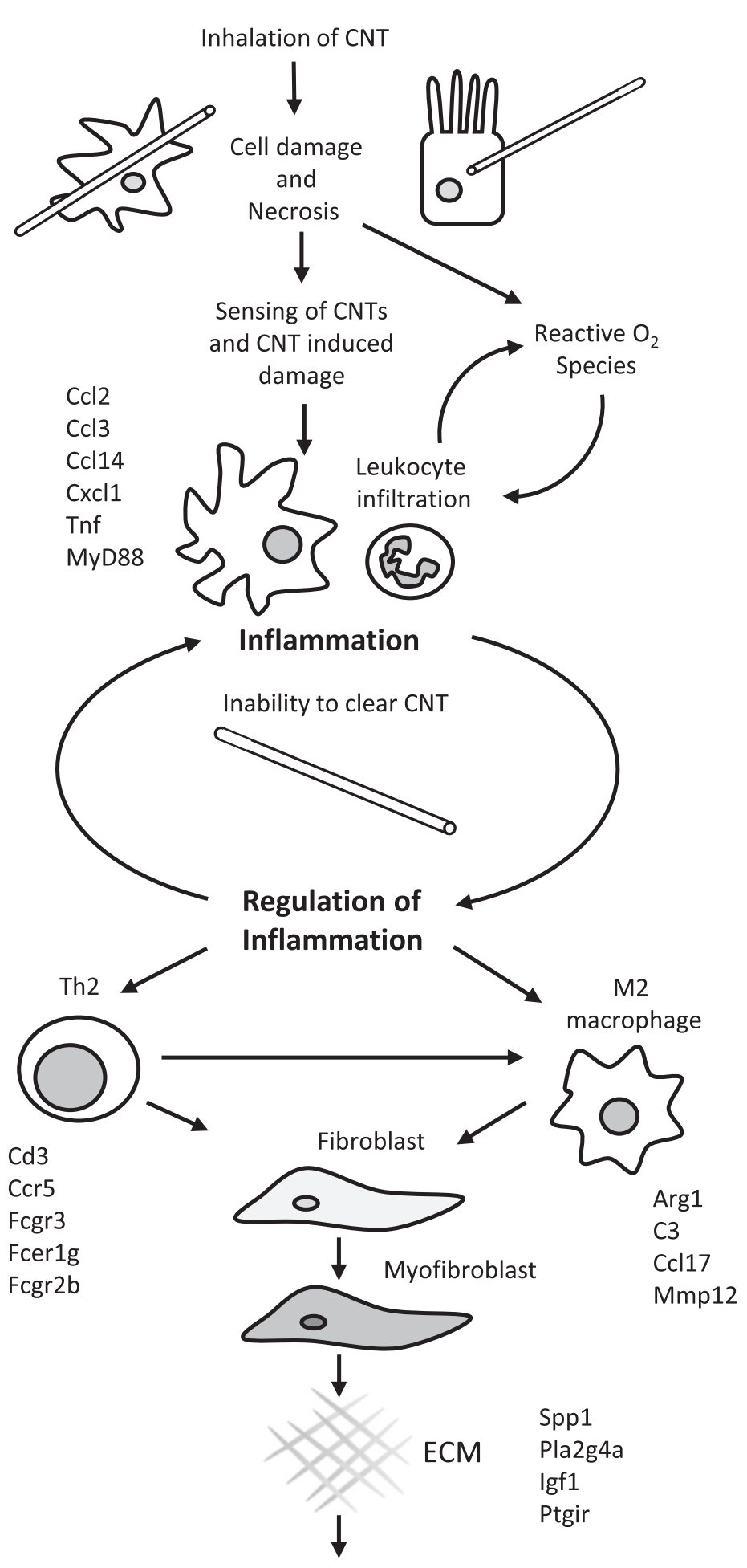

Fibrosis 
(See figure on previous page.)

Fig. 6 The cluster analysis indicates a potential pathway for MWCNT-induced fibrosis based on two distinct phases. In summary of the results of the cluster analysis, a pathway can be constructed representing the two phases of the lung response to the MWCNT with relation to the disease models that share similar gene expression. The genes and GOs identified in the meta-analysis are organized into the events along the pathway where they are likely involved. Due to the lack of clustering, the response to nanoTiO 2 and $\mathrm{CB}$ could not be similarly summarized

MWCNTs, but the extent of the toxic outcomes of this response may not be fully realized in isolation. The effects induced in a MWCNT exposed lung in the context of other diseases should be considered to fully appreciate the breadth of MWCNT-induced pathology.

\section{Conclusions}

In summary, the findings of our meta-analysis identified genes and biological processes involved in two distinct phases of the pulmonary response to MWCNTs. This response was characterized by its similarity to existing models of lung disease and was distinct from the response elicited by nanoTiO $\mathrm{T}_{2}$ and $\mathrm{CB}$ nanoparticles. Some of the key genes and GOs identified in this study are depicted in Fig. 6, which describes a possible mechanism of pathology. Inflammation and Th2 responses have previously been implicated in the progression of pulmonary fibrosis [27], and the current analysis also highlights the potential importance of alternatively activated macrophages in this process. The cluster analysis provided new insights into the mechanisms of disease engaged by a nanomaterial capable of inducing fibrosis and highlighted how these mechanisms are not engaged by nanoparticles that do not induce fibrosis.

The systematic and comparative meta-profiling of a small set of publicly available microarray datasets enabled characterization of a transcriptional signature that is shared between various lung disease models and one that is essential to MWCNT-induced lung fibrosis. The observation of generalized activation of specific gene mechanisms regardless of their specific properties suggests that these genes and mechanisms are strongly associated with lung fibrosis. As the public repository of transcriptome data becomes populated, the simple framework described here for comparing and assessing the intersections of multiple gene expression patterns from different datasets will enable effective differentiation between the disease inducing and benign ENMs, and aid in prioritizing of ENMs for further investigation. It is important to note that the approach proposed is not an in silico computational approach and requires tissue-specific gene expression profiling following exposure to novel ENMs. However, it is proposed that the strategy (short term in vivo tissue transcriptomics combined with meta-analysis) can be used as an effective first tier screening of new ENMs that exhibit higher potential to induce pulmonary pathology. The study results presented here reflect lung responses to ENMs in mouse model. However, many of the significantly perturbed pro-fibrotic genes and pathways identified are known to be associated with lung fibrosis in humans. Conditional to appropriate validation, some of the genes may potentially be used to support future biomonitoring and surveillance efforts for ENMs.

\section{Ethic approval and consent to participate}

All studies selected for the analysis obtained proper ethics approval from their respective institutions animal ethics boards. No animal experiments were conducted in addition to the previously published studies.

\section{Availability of data and material}

All experimental data is available through GEO under the GSE identification numbers outlined in Table 1.

\section{Additional file}

Additional file 1: Table S1. A list of 2334 differentially expressed genes that were consistent to all of the microarray platforms employed in the studies included in the meta-analysis. (PPTX $123 \mathrm{~kb}$ )

\section{Abbreviations}

BAL: bronchoalveolar lavage; CB: carbon black; CNTs: carbon nanotubes; DEGs: differentially expressed genes; ENMs: engineered nanomaterials; GEO: Gene Expression Omnibus; GOs: gene ontologies; IPA: Ingenuity Pathway Analysis; LPS: lipopolysaccharide; MWCNTs: multi-walled carbon nanotubes; NM: nanomaterial; $\mathrm{TiO}_{2}$ : titanium dioxide.

\section{Competing interests}

Authors have no competing interests to declare.

\section{Authors' contributions}

J.K.N. analyzed the data and contributed to writing the manuscript. A.W. compiled the selected studies and generated the cluster analysis. C.L.Y. contributed to manuscript development. H.W. and U.V. contributed analysis input and commented on the manuscript. S.H. conceptualized the experiments, aided in study selection, analyzed data, and co-wrote the manuscript. All authors have read and approved the manuscript.

\section{Acknowledgements}

We thank Marc Beal and Julie Buick for helpful comments on the manuscript.

\section{Funding}

Funding was provided under the Health Canada Genomics Research and Development Initiative; Health Canada Chemical Management Plan-Nano.

\section{Author details}

'Environmental Health Science and Research Bureau, Health Canada, Ottawa, ON K1A 0K9, Canada. ${ }^{2}$ National Research Centre for the Working Environment, Lerso Parkallé 105, Copenhagen DK-2100, Denmark. ${ }^{3}$ Department of Public Health, University of Copenhagen, Copenhagen K 
DK-1353, Denmark. ${ }^{4}$ Department of Micro- and Nanotechnology, Technical University of Denmark, DK-2800 Kgs., Lyngby, Denmark.

\section{Received: 19 February 2016 Accepted: 5 May 2016 Published online: 11 May 2016}

\section{References}

1. Vance ME, Kuiken T, Vejerano EP, McGinnis SP, Hochella MF, Rejeski D, Hull MS. Nanotechnology in the real world: Redeveloping the nanomaterial consumer products inventory. Beilstein J Nanotechnol. 2015;6:1769-80.

2. Oberdörster G, Oberdörster E, Oberdörster J. Nanotoxicology: An emerging discipline evolving from studies of ultrafine particles. Environ Health Perspect. 2005;113:823-39.

3. Donaldson $\mathrm{K}$, Tran CL. Inflammation caused by particles and fibers. Inhal Toxicol. 2002;14:5-27.

4. Yamashita K, Yoshioka Y, Higashisaka K, Morishita Y, Yoshida T, Fujimura M, Kayamuro H, Nabeshi H, Yamashita T, Nagano K, Abe Y, Kamada H, Kawai Y, Mayumi T, Yoshikawa T, Itoh N, Tsunoda SI, Tsutsumi Y. Carbon nanotubes elicit DNA damage and inflammatory response relative to their size and shape. Inflammation. 2010:33:276-80.

5. Kaewamatawong T, Shimada A, Okajima M, Inoue H, Morita T, Inoue K, Takano H. Acute and subacute pulmonary toxicity of low dose of ultrafine colloidal silica particles in mice after intratracheal instillation. Toxicol Pathol. 2006;34:958-65.

6. Stone V, Pozzi-Mucelli S, Tran L, Aschberger K, Sabella S, Vogel U, Poland C, Balharry D, Fernandes T, Gottardo S, Hankin S, Hartl MGJ, Hartmann N, Hristozov D, Hund-Rinke K, Johnston H, Marcomini A, Panzer O, Roncato D, Saber AT, Wallin H, Scott-Fordsmand JJ. ITS-NANO-prioritising nanosafety research to develop a stakeholder driven intelligent testing strategy. Part Fibre Toxicol. 2014;11:9.

7. Halappanavar S, Saber AT, Decan N, Jensen KA, Wu D, Jacobsen NR, Guo C, Rogowski J, Koponen IK, Levin M, Madsen AM, Atluri R, Snitka V, Birkedal RK Rickerby D, Williams A, Wallin H, Yauk CL, Vogel U. Transcriptional profiling identifies physicochemical properties of nanomaterials that are determinants of the in vivo pulmonary response. Environ Mol Mutagen. 2015;56:245-64.

8. Poulsen SS, Saber AT, Williams A, Andersen O, Købler C, Atluri R, Pozzebon ME, Mucelli, SP, Simion M, Rickerby D, Mortensen A, Jackson P, Kyjovska ZO, Mølhave K, Jacobsen NR, Jensen K a., Yauk CL, Wallin H, Halappanavar S, Vogel U. MWCNTs of different physicochemical properties cause similar inflammatory responses, but differences in transcriptional and histological markers of fibrosis in mouse lungs. Toxicol Appl Pharmacol. 2015;284:16-32.

9. Puzyn T, Leszczynska D, Leszczynski J. Toward the development of "NanoQSARs": Advances and challenges. Small. 2009:5:2494-509.

10. Bourdon J a, Halappanavar S, Saber AT, Jacobsen NR, Williams A, Wallin $H_{\text {, }}$ Vogel U, Yauk CL. Hepatic and pulmonary toxicogenomic profiles in mice intratracheally instilled with carbon black nanoparticles reveal pulmonary inflammation, acute phase response, and alterations in lipid homeostasis. Toxicol Sci. 2012;127:474-84.

11. Husain M, Saber AT, Guo C, Jacobsen NR, Jensen $K$ a, Yauk CL, Williams A, Vogel U, Wallin $\mathrm{H}$, Halappanavar S. Pulmonary instillation of low doses of titanium dioxide nanoparticles in mice leads to particle retention and gene expression changes in the absence of inflammation. Toxicol Appl Pharmacol. 2013;269:250-62.

12. Jackson P. Hougaard KS, Vogel U, Wu D, Casavant L, Williams A, Wade M, Yauk $\mathrm{CL}$, Wallin $\mathrm{H}$, Halappanavar S. Exposure of pregnant mice to carbon black by intratracheal instillation: Toxicogenomic effects in dams and offspring. Mutat Res Genet Toxicol Environ Mutagen. 2012;745:73-83.

13. Halappanavar S, Jackson P, Williams A, Jensen KA, Hougaard KS, Vogel U, Yauk CL, Wallin H. Pulmonary response to surface-coated nanotitanium dioxide particles includes induction of acute phase response genes, inflammatory cascades, and changes in microRNAs: A toxicogenomic study. Environ Mol Mutagen. 2011;52(6):425-39.

14. Guo NL, Wan Y-W, Denvir J, Porter DW, Pacurari M, Wolfarth MG, Castranova $\checkmark$, Qian Y. Multiwalled carbon nanotube-induced gene signatures in the mouse lung: potential predictive value for human lung cancer risk and prognosis. J Toxicol Environ Heal Part A. 2012;75:1129-53.

15. Erdely A, Antonini JM, Salmen-Muniz R, Liston A, Hulderman T, Simeonova PP, Kashon ML, Li S, Gu JK, Stone S, Chen BT, Frazer DG, Zeidler-Erdely PC. Type I interferon and pattern recognition receptor signaling following particulate matter inhalation. Part Fibre Toxicol. 2012;9:25.
16. Zeidler-Erdely PC, Kashon ML, Li S, Antonini JM. Response of the mouse lung transcriptome to welding fume: effects of stainless and mild steel fumes on lung gene expression in A/J and C57BL/6 J mice. Respir Res. 2010;1 1:70.

17. Lewis CC, Yang JYH, Huang X, Banerjee SK, Blackburn MR, Baluk P, McDonald DM, Blackwell TS, Nagabhushanam V, Peters W, Voehringer D, Erle DJ. Disease-specific gene expression profiling in multiple models of lung disease. Am J Respir Crit Care Med. 2008;177:376-87.

18. Thomson EM, Williams A, Yauk CL, Vincent R. Overexpression of tumor necrosis factor-a in the lungs alters immune response, matrix remodeling, and repair and maintenance pathways. Am J Pathol. 2012;180:1413-30.

19. Husain M, Kyjovska ZO, Bourdon-Lacombe J, Saber AT, Jensen KA, Jacobsen NR, Williams A, Wallin H, Halappanavar S, Vogel U, Yauk CL. Carbon black nanoparticles induce biphasic gene expression changes associated with inflammatory responses in the lungs of C57BL/6 mice following a single intratracheal instillation. Toxicol Appl Pharmacol. 2015;289(3):573-88.

20. Yang YH, Dudoit S, Luu P, Lin DM, Peng V, Ngai J, Speed TP. Normalization for CDNA microarray data: a robust composite method addressing single and multiple slide systematic variation. Nucleic Acids Res. 2002:30:e15.

21. R Core Team: R. A language and environment for statistical computing. 2014.

22. Gautier L, Cope L, Bolstad BM, Irizarry RA. Affy-analysis of Affymetrix GeneChip data at the probe level. Bioinformatics. 2004;20:307-15.

23. Du P, Kibbe WA, Lin SM. Lumi: a pipeline for processing Illumina microarray. Bioinformatics. 2008:24:1547-8.

24. Shi L, Jones WD, Jensen RV, Harris SC, Perkins RG, Goodsaid FM, Guo L, Croner LJ, Boysen C, Fang H, Qian F, Amur S, Bao W, Barbacioru CC, Bertholet V, Cao XM, Chu T-M, Collins PJ, Fan X-H, Frueh FW, Fuscoe JC, Guo X, Han J, Herman D, Hong H, Kawasaki ES, Li Q-Z, Luo Y, Ma Y, Mei N, et al. The balance of reproducibility, sensitivity, and specificity of lists of differentially expressed genes in microarray studies. BMC Bioinformatics. 2008;9 Suppl 9:S10.

25. Shannon P, Markiel A, Ozier O, Baliga NS, Wang JT, Ramage D, Amin N, Schwikowski B, Ideker T. Cytoscape: A Software Environment for Integrated Models of Biomolecular Interaction Networks Cytoscape: A Software Environment for Integrated Models of Biomolecular Interaction Networks. Genome Res. 2003:13(11):2498-504.

26. Bindea G, Mlecnik B, Hackl H, Charoentong P, Tosolini M, Kirilovsky A, Fridman WH, Pagès F, Trajanoski Z, Galon J. ClueGO: A Cytoscape plug-in to decipher functionally grouped gene ontology and pathway annotation networks. Bioinformatics. 2009;25:1091-3.

27. Wynn $T$ a. Fibrotic disease and the $T(H) 1 / T(H) 2$ paradigm. Nat Rev Immunol. 2004;4:583-94.

28. Ryman-Rasmussen JP, Tewksbury EW, Moss OR, Cesta MF, Wong B a, Bonner JC. Inhaled multiwalled carbon nanotubes potentiate airway fibrosis in murine allergic asthma. Am J Respir Cell Mol Biol. 2009:40:349-58.

29. Mercer RR, Hubbs AF, Scabilloni JF, Wang L, Battelli L a, Friend S, Castranova $V$, Porter DW. Pulmonary fibrotic response to aspiration of multi-walled carbon nanotubes. Part Fibre Toxicol. 2011;8:21.

30. Murray L a, Rosada R, Moreira AP, Joshi A, Kramer MS, Hesson DP, Argentieri RL, Mathai S, Gulati M, Herzog EL, Hogaboam CM. Serum amyloid P therapeutically attenuates murine bleomycin-induced pulmonary fibrosis via its effects on macrophages. PLoS One. 2010;5:1-9.

31. Pechkovsky DV, Prasse A, Kollert F, Engel KMY, Dentler J, Luttmann W, Friedrich K, Müller-Quernheim J, Zissel G. Alternatively activated alveolar macrophages in pulmonary fibrosis-mediator production and intracellular signal transduction. Clin Immunol. 2010;137:89-101.

32. Thannickal VJ, Pardo A, Zisman DA, Martinez FJ, lii JPL. Idiopathic pulmonary fibrosis. Drugs. 2004;64:405-30

33. Walter N, Collard HR, King TE. Current perspectives on the treatment of idiopathic pulmonary fibrosis. Proc Am Thorac Soc. 2006;3:330-8.

34. The Idiopathic Pulmonary Fibrosis Clinical Research Network: Prednisalone, Azathioprine, and $\mathrm{N}$-acetylcysteine for pulmonary fibrosis. N Engl J Med. 2012;366(21):1968-77.

35. Hoyles RK, Ellis RW, Wellsbury J, Lees B, Newlands P, Goh NSL, Roberts C, Desai S, Herrick AL, McHugh NJ, Foley NM, Pearson SB, Emery P, Veale DJ, Denton CP, Wells AU, Black CM, Du Bois RM. A multicenter, prospective, randomized, doubleblind, placebo-controlled trial of corticosteroids and intravenous cyclophosphamide followed by oral azathioprine for the treatment of pulmonary fibrosis in scleroderma. Arthritis Rheum. 2006;54:3962-70.

36. Sica A, Mantovani A. Macrophage plasticity and polarization: In vivo veritas. J Clin Invest. 2012;122(3):787-95, 
37. Donaldson K, Murphy F a, Duffin R, Poland C a. Asbestos, carbon nanotubes and the pleural mesothelium: a review of the hypothesis regarding the role of long fibre retention in the parietal pleura, inflammation and mesothelioma. Part Fibre Toxicol. 2010;7:5.

38. Donaldson K, Poland C a, Murphy F a, MacFarlane M, Chernova T, Schinwald A. Pulmonary toxicity of carbon nanotubes and asbestos - Similarities and differences. Adv Drug Deliv Rev. 2013;65:2078-86.

39. Saber AT, Jensen KA, Jacobsen NR, Birkedal R, Mikkelsen L, Møller P, Loft S, Wallin $\mathrm{H}$, Vogel U. Inflammatory and genotoxic effects of nanoparticles designed for inclusion in paints and lacquers. Nanotoxicology. 2012;6(5):453-71.

40. Jackson P, Hougaard KS, Boisen AMZ, Jacobsen NR, Jensen KA, Møller P Brunborg G, Gutzkow KB, Andersen O, Loft S, Vogel U, Wallin H. Pulmonary exposure to carbon black by inhalation or instillation in pregnant mice: Effects on liver DNA strand breaks in dams and offspring. Nanotoxicology. 2012;6:486-500.

41. Pacurari $M$, Qian $Y$, Porter DW, Wolfarth $M$, Wan $Y$, Luo D, Ding M, Castranova V, Guo NL. Multi-walled carbon nanotube-induced gene expression in the mouse lung: Association with lung pathology. Toxicol Appl Pharmacol. 2011;255:18-31.

42. Sargent LM, Porter DW, Staska LM, Hubbs AF, Lowry DT, Battelli L, Siegrist K, Kashon, ML, Mercer RR, Bauer AK, Chen BT, Salisbury JL, Frazer D, McKinney W, Andrew M, Tsuruoka S, Endo M, Fluharty KL, Castranova V, Reynolds SH. Promotion of lung adenocarcinoma following inhalation exposure to multiwalled carbon nanotubes. Part Fibre Toxicol. 2014;11:1-18.

43. Beamer C a, Girtsman T a, Seaver BP, Finsaas KJ, Migliaccio CT, Perry VK, Rottman JB, Smith DE, Holian A. IL-33 mediates multi-walled carbon nanotube (MWCNT)-induced airway hyper-reactivity via the mobilization of innate helper cells in the lung. Nanotoxicology. 2013;7:1070-81.

44. Ronzani C, Casset A, Pons F. Exposure to multi-walled carbon nanotubes results in aggravation of airway inflammation and remodeling and in increased production of epithelium-derived innate cytokines in a mouse model of asthma. Arch Toxicol. 2014;88:489-99.

45. Inoue Kl, Koike E, Yanagisawa R, Hirano S, Nishikawa M, Takano H. Effects of multi-walled carbon nanotubes on a murine allergic airway inflammation model. Toxicol Appl Pharmacol. 2009:237:306-16.

46. Sanpui P, Zheng X, Loeb JC, Bisesi Jr JH, Khan I a, Afrooz a RMN, Liu K, Badireddy AR, Wiesner MR, Ferguson PL, Saleh NB, Lednicky J a, Sabo-Attwood T. Single-walled carbon nanotubes increase pandemic influenza A H1N1 virus infectivity of lung epithelial cells. Part Fibre Toxicol. 2014;11:66.

47. Han SG, Andrews R, Gairola CG. Acute pulmonary response of mice to multi-wall carbon nanotubes. Inhal Toxicol. 2010;22:340-7.

\section{Submit your next manuscript to BioMed Central and we will help you at every step:}

- We accept pre-submission inquiries

- Our selector tool helps you to find the most relevant journal

- We provide round the clock customer support

- Convenient online submission

- Thorough peer review

- Inclusion in PubMed and all major indexing services

- Maximum visibility for your research

Submit your manuscript at www.biomedcentral.com/submit

) Biomed Central 